\title{
HISTÓRIA DA MATEMÁTICA EM UM PROGRAMA DE INICIAÇÃO CIENTÍFICA JÚNIOR
}

\section{HISTORY OF MATHEMATICS AND SCIENTIFIC RESEARCH JUNIOR PROJECT}

\author{
Davidson Paulo Azevedo Oliveira ${ }^{1}$ \\ Instituto Federal de Minas Gerais - Campus Ouro Preto \\ Maria Maroni Lopes ${ }^{2}$ \\ Universidade Federal do Rio Grande do Norte - Campus Caicó/RN
}

\begin{abstract}
Resumo
Este artigo discute alguns resultados relativos a um projeto de pesquisa de iniciação científica júnior no qual foi investigado a História das equações do segundo grau. Objetivou-se analisar algumas das competências e habilidades que podem ser desenvolvidas por alunos do Ensino Médio em programas dessa natureza. O estudante realizou pesquisas bibliográficas e o processo foi avaliado qualitativamente. Apresentamse, como resultados, alguns métodos de resolução de equação do segundo grau além de discutirmos sobre o uso da História da Matemática na Educação Básica que não se restringe ao desenvolvimento de competências e habilidades somente matemáticas.
\end{abstract}

Palavras-chave: História da Matemática; Iniciação Científica Júnior; Equações do segundo grau.

\begin{abstract}
This paper presents some results of a research project regarding the scientific research junior project with methods for solving quadratic equation along the History of Mathematics. The main goal is to discuss some skills and abilities that can be developed by high school students in junior research programs. The student carries out a literature review and the research process is evaluated qualitatively. Presents results as some methods of solving the quadratic equation we get beyond the completion of the possibility of using the History of Mathematics in basic education that is not restricted to skills development and math skills only.
\end{abstract}

Keywords: History of Mathematics; Inicial Scientific Research; Second degree equations.

\footnotetext{
${ }^{1}$ E-mail - davidson.oliveira@ifmg.edu.br

${ }^{2}$ E-mail - marolopes@gmail.com.
} 


\section{Introdução}

Busca-se, por meio dos projetos de iniciação científica no Ensino Médio, despertar a competência científica dos alunos fortalecendo a divulgação de informações e conhecimentos, desenvolver atitudes, habilidades além de valores necessários à educação científica e tecnológica dos mesmos. E ainda, favorecer a vivência dos jovens alunos em ambientes universitários e de pesquisa.

Assim, objetivou-se nesse estudo apresentar e analisar o desenvolvimento e a participação de um aluno do Ensino Médio inserido em um Programa Institucional de Bolsas de Iniciação Científica Júnior (PIBIC-Jr) fomentado por um Instituto Federal de Ciência e Tecnologia.

O projeto apresenta como propostas de trabalho:

1) Estudar, em conjunto com o aluno do Ensino Médio, alguns métodos históricos para resolução de equação do segundo grau a fim de elaborar material para ser utilizado em sala de aula sobre o assunto;

2) Analisar algumas das competências e habilidades que podem ser desenvolvidas por alunos do Ensino Médio quando a História da Matemática é utilizada enquanto recurso didático pelo professor.

Para isso, um aluno da educação básica foi selecionado como bolsista de tal programa para essa pesquisa. Assim, iniciou-se o estudo da história das equações do segundo grau. Sabe-se que normalmente nas escolas brasileiras a forma usualmente ensinada para se resolver equações do segundo grau é pela utilização e aplicação direta da Fórmula de Bháskarasendo vista de modo geral de uma maneira natural tanto pelos alunos quanto pelos professores. Porém, em sua grande maioria, de forma mecânica. Decoramos a fórmula e aplicamos na resolução de questões. Segundo Miguel e Miorim (2008) foi na obra Elementos de álgebra de Perez y Marin publicada em 1928 que foi encontrada, pela primeira vez, a denominação de fórmula de Bháskara para a fórmula resolutiva de equações quadráticas no Brasil.

Em nossa prática, tanto como professores da educação básica quanto na formação inicial de professores de Matemática observa-se que não há questionamentos no momento de se resolver equações do segundo grau, simplesmente usa-se uma fórmula decorada na 


\section{Davidson Paulo Azevedo Oliveira e Maria Maroni Lopes}

História da matemática em um programa de iniciação científica júnior

abordagem do tema no Ensino Fundamental. O que pode vir a ser motivo de dificuldades de sentido do conteúdo para o aluno.

Isso posto, pretendeu-se com a pesquisa desenvolver uma proposta que nos auxiliasse a atentarmos, e também aos alunos, para o desenvolvimento histórico de tal fórmula e de diferentes modos de resolução encontradas em outros povos e culturas ao longo da história e da atualidade. Buscamos, juntamente com o aluno bolsista, métodos de resolução de equação do segundo grau em outras civilizações do passado, o que pode ser interessante e, de acordo com Fossa (2006, p.138), “É decerto, na história da matemática que vemos como a matemática faz parte da cultura humana e isto certamente pode aumentar o interesse que o aluno terá pela matemática". Assim, a História da Matemática pode ser uma aliada do professor para humanizar a matemática, ou seja, mostrar aos alunos que ela é uma construção humana e, com isso, passível de erros.

Sobretudo em nosso estudo, a resolução de equações quadráticas ao longo da história como é ressaltada na pesquisa realizada por Refatti e Bisognin (2005) que considera esse estudo valioso como instrumento didático. Segundo esses autores:

Quando se estuda equação polinomial do segundo grau, geralmente, utiliza-se
a representação europeia e a forma de resolução dada pelos hindus. Nesse
estudo sobre a origem da equação quadrática, observou-se a preocupação que
os matemáticos de diferentes épocas tiveram ao tentar solucionar esse
problema. Assim, esta história pode ser considerada um valioso instrumento
para o ensino/aprendizado da própria Matemática. (REFATTI e BISOGNIN,
2005, p.93)

Porém conforme afirmam alguns pesquisadores não existe literatura suficiente disponível no Brasil sobre História da Matemática (BROLEZZI, 1991; MIGUEL, 1997; MENDES, 2006). Nesse sentido, buscamos uma seleção de materiais voltados à história das equações do segundo grau e encontramos alguns trabalhos na área (ex. CARVALHO, MIORIM, BARONE, MUNSIGATTI, BEGINATO, 2001; NOBRE, 2006; RADFORD e GUÉRETTE, 2000; REFATTI e BISOGNIN, 2005; PEDROSO, 2010). Contudo, esses trabalhos não apresentam propostas metodológicas sobre o ensino ou atividades a serem utilizadas em sala de aula com a história da matemática enquanto recurso metodológico de ensino.

Nesse sentido, Miguel (1997) salienta que "a natureza da literatura histórica disponível sobre a História da Matemática a torna particularmente imprópria à utilização didática" (p.95). Isso nos levou a estudar métodos de resolução de equações do segundo grau ao longo da história por meio do desenvolvimento uma pesquisa de Iniciação 
Davidson Paulo Azevedo Oliveira e Maria Maroni Lopes

História da matemática em um programa de iniciação científica júnior

Científica Júnior visando à elaboração de um material que pudesse ser utilizado como recurso metodológico de ensino.

A falta de material destinado a professores interessados em trabalhar com a História da Matemática em sala de aula é enfatizada por Brolezzi (1991) e, mais recentemente, por Mendes (2006) que ressaltam a importância do conhecimento da História da Matemática pelos professores, e reafirmam a insuficiência de material destinado a esse fim. Miguel (1997), entre argumentos questionadores sobre as potencialidades pedagógicas da História da Matemática, argumenta que o ensino dessa disciplina torna-se problemático "devido à quase ausência de literatura adequada sobre a história da matemática anterior aos dois últimos séculos" (p. 95). Esse fato "impedirá a utilização pedagógica da história porque a maior parte daquilo que é usualmente ensinado de matemática em nossas escolas de $1^{\circ}$ e $2^{\circ}$ graus pertence a esse período" (MIGUEL, 1997, p. 95).

Apesar de existir um número considerável de livros sobre a História da Matemática, escritos em português e espanhol, para que os professores possam pesquisar e preparar as suas aulas, Silva (2001) destaca a dificuldade do acesso e a escassez de fontes sendo que essas obras "não são facilmente encontráveis em livrarias e mesmo em bibliotecas” (p. 150). Além da falta de material que auxilie os professores em sala de aula, Silva (2010) também aponta outros fatores que indicam a fragilidade da História da Matemática em cursos de formação de professores. Esses fatores são:

(...) a falta de abordagens históricas nos cursos de Matemática; a permanência [da História da Matemática], em alguns casos, como disciplina optativa; a nãovalorização da disciplina de história da Matemática; a falta de professores motivados em ministrá-la. A dificuldade de se formar grupos de pesquisas em história da Matemática; dificuldades de encontrarmos livros-texto de história da Matemática e que ajudem o professor em sala de aula (SILVA, 2007, p.110).

Porém, se por um lado os professores esbarram em diversos obstáculos para a utilização pedagógica da História da Matemática, por outro lado, existe um campo fértil de pesquisa nessa área de estudo. O projeto que hora analisamos propôs um processo de estudo e produção de conhecimento ao mesmo tempo em que pretendia identificar modos históricos de resolver equações do segundo grau visando à produção de material didático sobre o tema. Pretendia-se promover no próprio processo de pesquisa a aprendizagem do bolsista sobre esses métodos e sobre o que é fazer pesquisa. Nesse sentido, trabalhar com textos sobre a história de cada época pode auxiliar os alunos no desenvolvimento das habilidades de ler e escrever. 
Segundo Bezerra (2008) a História da Matemática auxiliaria ao professor e ao aluno para que a Matemática não seja misteriosa e distante. Afirma que:

\footnotetext{
No Brasil, há uma grande dificuldade de se encontrar materiais sobre a história da matemática. Assim, o professor é condicionado a utilizar o material disponível no mercado. É importante mencionar que normalmente ele faz uso desse material mais como uma ferramenta mecânica sem fazer, no entanto, uso da história (BEZERRA, 2008, p.28).
}

No entanto, esse argumento deveria servir de incentivo e apelo à formação de grupos de pesquisa em história da matemática e não funcionar como um obstáculo ao desenvolvimento das relações entre história da matemática e situações pedagógicas em sala de aula (MIGUEL, 1997).

Neto (2009, p.43) também destaca a falta de materiais que têm por base a história da matemática e o modo como deveriam ser produzidos. De acordo com esse autor os materiais "são escassos no domínio público e professores de matemática e educadores matemáticos devem desenvolver, individualmente ou em grupos, seus próprios materiais nessa categoria e torná-los disponíveis para uma comunidade mais ampla." O autor destaca, ainda, a linguagem acessível ao professor que deveria existir nos materiais disponíveis, o que pode ser realizado com o trabalho conjunto de professor e alunos do Ensino Médio.

\section{O que nos referencia teoricamente}

Objetivo do PIBIC Jr no Instituto Federal em questão é de promover a iniciação à pesquisa de alunos das várias modalidades de ensino ofertadas no campus; contribuir para a formação de recursos humanos para atuação na pesquisa e/ou em qualquer outra atividade profissional; envolver alunos nas atividades científicas e tecnológicas. Além disso, como citado anteriormente, o nosso estudo em específico objetivou investigar métodos históricos de resolução de Equação do $2^{\circ}$ grau e ainda, produzir material de apoio aos professores da educação básica.

Diante do exposto, direcionamos a nossa investigação aos estudos de um grupo de pesquisa dinamarquês que tem analisado o papel da História da Matemática no ensino e na aprendizagem dessa disciplina, pois seu uso pedagógico é sugerido em documentos oficiais nesse país. Assim, no artigo Reflections on and benefits of uses of history in mathematics education exemplified by two types of student work in upper secondary 


\section{Davidson Paulo Azevedo Oliveira e Maria Maroni Lopes}

História da matemática em um programa de iniciação científica júnior

school, Kjeldsen (2011) discute sobre o uso da História da Matemática enquanto recurso didático nas aulas de Matemática no ensino secundário. Apresenta projetos nos quais pretendia desenvolver competências e habilidades nos estudantes que podem ser ressaltadas se a História da Matemática for utilizada como aliada do professor em sua metodologia de ensino.

Nesse sentido, Kjeldsen (2011) tinha o objetivo de aumentar a competência dos alunos para trabalhos em equipe; melhorar a aprendizagem dos alunos de forma independente; reforçar as competências dos alunos em apresentações orais; ganhar competências de uso das ferramentas da informática, como por exemplo, o uso do software Office com os recursos do PowerPoint; construir competências nos alunos de forma que eles percebam a evolução da matemática ao longo do tempo; e desenvolver uma consciência nos alunos de forma a entenderem que os resultados matemáticos se desenvolvem em uma interação com a cultura e sociedade.

Assim, com base na falta de material disponível em Língua Portuguesa sobre História da Equação do $2^{\circ}$ Grau e baseados nos estudos de Kjeldsen (2011), buscamos uma pesquisa na qual tanto a produção de material com linguagem apropriada quanto às competências que os alunos podem desenvolver com o uso dessa metodologia de ensino fossem visadas. No entanto, esta pesquisa foca no desenvolvimento de competências e habilidades de um aluno, o bolsista, que trabalhará em conjunto com o orientador a fim de atingir os objetivos a seguir descritos.

Além dos argumentos de Kjeldsen (2011) nos apoiamos teoricamente no trabalho de Jankvist (2009) que apresenta dois argumentos para a História da Matemática em sala de aula, a história como ferramenta e como objetivo, além de propor três abordagens para o uso da História da Matemática em sala de aula, Iluminação, Modular e Baseada na História. Esses argumentos e abordagens se complementam e formam seis conexões possíveis de porque se utilizar a história da matemática e como ela pode ser utilizada (fig.1). 


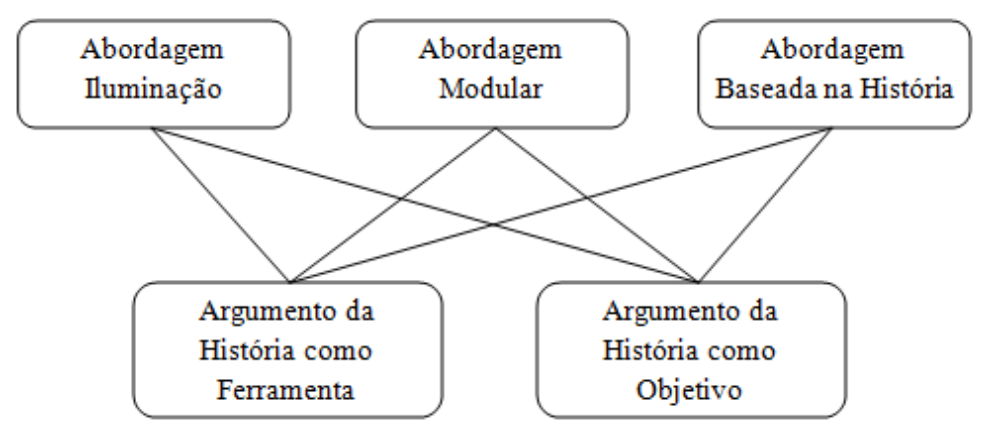

FIGURA 1: As possíveis conexões entre as categorias de Jankvist.

FONTE: Jankvist (2009, p..251)

Os argumentos que justificam o porquê de a História da Matemática poder ser (e deveria ser) considerada uma metodologia de ensino:

a) História como ferramenta é utilizada como uma metodologia de ensino que auxilia o professor no ensino da matemática e contém argumentos de como os alunos aprendem matemática (JANKVIST, 2009). Nesse sentido, pode-se mostrar que a matemática é uma criação humana, motivar os estudantes, pois entendem que até os matemáticos profissionais são passíveis de erros e, por fim, pode ser um auxílio na identificação de alguns dos obstáculos epistemológicos dos estudantes;

b) História como objetivo salienta que o ensino de história não deveria ser um tópico independente, o foco está no desenvolvimento de aspectos da matemática como disciplina. Objetiva-se mostrar aos estudantes que é uma construção humana que depende de cultura e tempo, a matemática não surge do além.

Porém, além da justificativa do uso pedagógico, deve-se ter em mente o modo como pode ser realizada, que são as abordagens apresentadas por Jankvist (2009):

i. Baseada na História: a História da Matemática não é necessariamente discutida, mas serve como um eixo orientador para o professor de modo a seguir fielmente a ordem histórica de construção de determinado tópico. Assemelha-se à abordagem genética.

ii. Iluminação: fatos isolados sobre a História da Matemática são apresentados sem o intuito de resolver problemas. São apresentados trechos históricos tais como nomes de matemáticos famosos, datas, trabalhos e eventos famosos, biografias e anedotas; 
iii. Modular: são apresentados estudos dedicados a História da Matemática com duração de algumas aulas, semanas ou cursos completos dedicados a um determinado tema, mas que não necessariamente precisam fazer parte do currículo. São tópicos prontos para serem utilizados pelos professores na sala de aula, no caso de um curto período de tempo, ou trabalho com fontes originais, para cursos maiores a depender do nível de estudo histórico dos alunos;

Baseada na História: a História da Matemática não é necessariamente discutida, mas serve como um eixo orientador para o professor.

Neste trabalho com o aluno bolsista a história foi utilizada como objetivo a fim de desenvolver as habilidades do discente em relação aos objetivos elencados por Kjeldsen (2011). Além de produzir um material didático que pode ser utilizado como ferramenta para professores interessados em uma abordagem histórica para a resolução de equações do segundo grau na sala de aula do Ensino Básico. Desse modo, o material produzido para os professores segue uma abordagem modular.

\section{Metodologia: como eram os encontros}

O presente trabalho foi desenvolvido em uma escola técnica federal do estado de Minas Gerais com um aluno matriculado, no início do projeto, na segunda série do Ensino Médio do curso de Mineração. A origem do fomento é da própria instituição que oferece, dentre outras, bolsa para o PIBIC-Jr, modalidade de pesquisa destinada a estudantes de cursos técnicos integrados (a partir do segundo ano) e exige uma carga horária semanal de 8 horas de dedicação. O projeto iniciou-se em abril de 2011 e finalizou em novembro de 2012 com a desistência do bolsista por motivos pessoais.

Foram realizadas leituras, apresentação de seminários semanais, com duração aproximada de duas horas, e escritas de relatórios sobre as atividades desenvolvidas em conjunto com o orientador. Após as discussões entre o aluno e o professor, dois textos eram elaborados: um visando a elaboração de um material para ser usado por alunos e por professores, portanto, com uma linguagem mais acessível no qual a História da Matemática pode ser utilizada como ferramenta. Outro com um caráter científico utilizando a linguagem acadêmica a fim de desenvolver algumas competências e habilidades no aluno, segundo as citadas por Kjeldsen (2011). 
Foram realizadas análises dos métods de Al-Khowarizmi e Descartes e posteriores adaptações para o uso do software GeoGebra. Para isso, contou-se com a participação de outro professor de matemática que possuía conhecimentos mais profundos sobre as ferramentas e recursos desse software.

Nesse sentido, os métodos estudados e demonstrados no trabalho de pesquisa foram realizados por meio da análise em livros para a busca de uma maior explicação e maior detalhamento para que possa compreender melhor cada método. Alguns artigos foram pesquisados em sites da internet como uma localização de que íamos estudar, já que é de mais fácil busca e um meio mais utilizado para pesquisa. A partir desses textos foram realizadas resenhas questionando e argumentando o que poderia ser melhorado no trabalho, depois era apresentado tudo em forma de seminário para maiores contribuições ao trabalho.

Assim, buscou-se atingir alguns dos objetivos destacados na pesquisa de Kjeldsen (2011) nos seminários com o orientador, e em eventos da área da Educação Matemática, com apresentações de trabalhos orais e posters. Incluindo um encontro internacional no qual o estudante teve contato com pesquisadores latino-americanos, de modo a reforçar competências do aluno em apresentações orais e utilização de tecnologias nas mesmas, escritas de relatórios e artigos, leituras minuciosas de outras pesquisas e contato com pesquisadores da área além de autonomia. Assim, em outubro de 2011 o aluno elaborou transparências em PowerPoint para que pudesse ser apresentado na Semana Nacional de Ciência e Tecnologia do instituto federal em questão, de modo a proporcionar ao bolsista, competências com o uso de ferramentas da informática (KJELDSEN, 2011).

Procurando também expandir o trabalho de forma que não apenas bolsista e orientador tomassem nota do conhecimento, mas os alunos em geral, foi realizado um trabalho com uma turma do Ensino Médio do curso de edificações do $1^{\circ}$ ano em relação ao método de Viétè. Buscou-se demonstrar um dos métodos para os alunos com acompanhamento do bolsista que analisou os resultados obtidos. Além disso, um curso em relação ao método empregado por Descartes foi ministrado a uma turma de alunos do primeiro período de Licenciatura em Matemática de uma Universidade Pública de Minas Gerais. 


\section{Davidson Paulo Azevedo Oliveira e Maria Maroni Lopes}

História da matemática em um programa de iniciação científica júnior

\section{Resultados da História como Objetivo e Ferramenta}

A História da Matemática utilizada também como objetivo e em uma abordagem modular nos proporcionou resultados em relação a outros métodos de resolução de equações do segundo grau além do uso da fórmula direta. Assim, focamos a história da matemática ora como ferramenta ora como objetivo. No entanto, apesar de ter sido utilizada como objetivo não foram utilizadas fontes primárias para a busca dos resultados apresentados. Estudamos os métodos dos Babilônios; de Al-Khowarizmi; de Descartes; de François Viétè; o fan-fan dos chineses (atualmente chamado de método de Horner); Egípcios; Leslie e dos Gregos.

O material elaborado a partir desse estudo apresenta no início de cada método um recorte do contexto sociocultural da época. Nesse sentido, Kjeldsen (2011) afirma que o trabalho com História da Matemática auxilia a desenvolver nos alunos consciência da importância da interação cultura e sociedade, além de perceberem a evolução do conhecimento matemático ao longo do tempo.

Assim, de acordo com Boyer (1996), os Babilônios resolviam as equações de modo algébrico, classificando as equações do segundo grau em três tipos: $x^{2}+p x=q$; $x^{2}=p x+q ; x^{2}+q=p x$. Essa classificação se deve ao fato deles não admitirem soluções negativas para as equações e, portanto, não resolviam equações do tipo $x^{2}+p x+q=0$ (BOYER, 1996). Além disso, os babilônios tinham um método próprio que não utilizava fórmulas, resolviam de modo retórico que se assemelhavam ao método algébrico (NOBRE, 2006). O segundo modo está relacionado com a maneira como Al-Khowarizmi resolvia as equações. Da mesma forma que os Babilônios, ele também as classificava em tipos: quadrados iguais a raízes $a x^{2}=b x$; quadrados iguais a números $a x^{2}=c$; raízes iguais a números $b x=c$; quadrados mais raízes iguais a números $a x^{2}+b x=c$; quadrados mais números iguais a raízes $a x^{2}+c=b x$; raízes mais números iguais a quadrados $b x+c=a x^{2}$ (NOBRE, 2006).

Além disso, ele resolvia essas equações de modo retórico e recorria ao método geométrico para justificar as passagens retóricas de resolução (CARVALHO, MIORIM, BARONE e MUSINGATTI, 2001). Como Al-Khowarizmi utilizava o método geométrico para justificar os seis casos de resolução, adaptou-se esse método para os dias atuais por meio do uso do software GeoGebra, sendo considerado mais uma ferramenta da informática a ser aprendida (KJELDSEN, 2011). 
Em seguida, tratou-se do método de Viéte que consiste em substituir a incógnita $x$ por outras duas incógnitas, $u$ e $v$, assim $x=u+v$ e, em seguida, encontrar o valor de uma das incógnitas em termos de $a, b$ e $c$ para a anulação da outra incógnita por meio da transformação de uma equação completa em incompleta, ou seja, uma equação do tipo $a x^{2}+b x+c=0$ em outra do tipo $a v^{2}=b$ (CARVALHO et al. 2001).

Outro método estudado foi o de René Descartes que utilizou técnicas do desenho geométrico para a resolução de equações do segundo grau por meio de régua graduada e compasso. Essas equações eram resolvidas por meio das relações métricas no triângulo retângulo e, também, com a aplicação da potência de ponto na circunferência (VARHIDY, 2010). Nesse sentido, de acordo com Boyer (1996), Descartes resolveu as equações do segundo grau no apêndice La Géométrie de sua obra Discurso do Método. De um modo geral, esse método foi realizado no GeoGebra, de modo a ser adaptado aos dias atuais.

O último método de resolução de equação do segundo grau estudado foi o desenvolvido pelos chineses e que, atualmente, é denominado de Método de Horner. Esse método permitia encontrar soluções aproximadas das equações ao arbitrar inicialmente um número como solução da equação e, a partir desse número, substituir a incógnita $x$ por: $x=2+d$ onde $d$ representa a diferença entre a solução verdadeira $x$ e a resposta arbitrada inicialmente. Resolve-se a equação em relação à nova incógnita $d$ e repete-se o processo até que a solução encontrada para $d$ seja nulo. O método estudado era conhecido como Fan-Fan e foi denominado pelo chinês de Chu Shih-Chieh. Boyer (1996) afirma que, posteriormente, Viétè utilizou esse método em sua obra De numerosa potestatum resolutione de 1600 . No ano de 1819 , esse método foi redescoberto pelo inglês Willian George Horner, sendo, por isso, nomeado atualmente, de método de Horner.

Os resultados alcançados em relação a História da Matemática como objetivo foram utilizados para a elaboração de um material no qual a História da Matemática era ferramenta e que foi enviado a professores que atuam em sala de aula do ensino regular, fundamental e médio, para que fosse por eles apreciado.

Os comentários de dois professores foram recebidos e julgaram interessantes as informações apresentadas e destacaram a possibilidade de uso desse material em suas salas de aula. Um deles afirmou o seguinte:

dei uma olhada neste material e avalio que está muito bom! Precisamos conversar sobre como foi esse processo, pelo jeito valeu muito a pena. 
Nota-se, portanto, o destaque dado pelo professor no estudo da História da Matemática como objetivo e de acordo com uma abordagem modular. Além disso, o interesse em relação ao processo vivenciado pelo estudante e as competências por ele desenvolvidas e que podem ser observadas de acordo com relatos do próprio aluno na seção seguinte.

\section{A História desenvolvendo competências e habilidades}

Apresentamos nesta seção os conhecimentos construídos por meio do projeto e ganhos que nos foram proporcionados. Elaborou-se, inicialmente, um questionário que foi respondido pelo bolsista, no qual foi pedido que o mesmo avaliasse o desenvolvimento do projeto, destacando as potencialidades e limitações na sua formação. De acordo com o depoimento do discente, existiram dois aspectos positivos que merecem destaque em relação a um programa de iniciação científica desenvolvido com alunos do Ensino Médio:

irei destacar os principais e que eu tenho muito a desenvolver cada vez mais. Como a maior capacidade de enxergar, de procurar saber sobre o que eu aprendia todos os dias, uma bolsa de pesquisa te dá uma amplitude muito grande sobre determinados assuntos. Outro foi o fato de procurar cada vez mais melhorar meu método de aprendizado a minha responsabilidade e muito o meu raciocínio.

(Comentário do aluno bolsista).

Esta afirmação do aluno nos aproxima do segundo objetivo de Kjeldsen (2011), no qual podemos perceber o aprendizado do discente de modo independente na medida em que ele busca seus próprios caminhos para o aprendizado de conhecimentos de matemática, de uso de ferramentas da informática e da própria escrita em Língua Portuguesa. Assim, torna-se ao mesmo tempo autônomo e com habilidades de trabalho em grupo, o que consideramos fundamental para pesquisadores para levantar hipóteses e investigar conjecturas.

No entanto, ele aponta alguns aspectos negativos em relação a trabalhos de iniciação científica com alunos do Ensino Básico, especialmente se tratando de escolas técnicas na qual os alunos possuem uma carga horária de oito horas diárias de dedicação. Ele ressalta que "o fato de conciliar o ensino médio técnico com uma bolsa científica é muito estressante e cansativo, tem de ter muita disposição e comprometimento para tais". 
Apesar da dificuldade de conciliação de um programa de iniciação científica com o ensino médio técnico ele recomenda a outros colegas e ressalta algumas competências e habilidades desenvolvidas e aprendidas que vão além do conteúdo de matemática, tais como a leitura e escrita de trabalhos acadêmicos. Segundo ele:

é um estudo muito cansativo conciliar o ensino médio com uma iniciação científica, mas isso nem se compara ao tanto que aprendi e desenvolvi como pesquisador e aluno. Aprendi a gostar de partes da matemática que não me dava muito bem e aprendi muito mais do que matemática. Enfim foi de grande aprendizado para mim e aconselharia sim quem se dispusesse de uma iniciação.

(Comentário do aluno bolsista).

Além do conhecimento matemático podemos notar a motivação pelo estudo que a História da Matemática despertou no estudante. Embora esse argumento da motivação seja delicado e mereça ser estudado com cautela (MIGUEL, 1997), se a História da Matemática for estudada como ferramenta ela pode motivar alguns alunos (JANKVIST, 2009). No caso que apresentamos o estudante não só ficou motivado, recomenda que deveria haver esse tipo de estudo na escola básica para que outros alunos se sentissem interessados pela matemática. Embora não vejamos a motivação como uma competência desenvolvida é um resultado relevante para pesquisadores preocupados com a História da matemática na sala de aula. De acordo com o ele:

Hoje questiono consideravelmente o quanto seria importante a aprendizagem dessa parte da matemática nas escolas em geral, apesar de não ser tão considerada, eu aprendi muito coisa que nem imaginava que poderiam apresentar tanta importância e uma melhor compreensão dos meus estudos. Aprendi muito sobre os principais estudiosos que se dedicavam para a demonstração e aplicação da matemática na nossa vida cotidiana.

(Comentário do aluno bolsista).

Vale ressaltar que a parte da matemática a que ele se refere é o estudo da História da Matemática. Além disso, novamente ele retoma a importância de aprender a desenvolver a aprendizagem autônoma que o fez ter interesse, inicialmente, por cursar Matemática na graduação. 
Quando comecei a me aprofundar mais e conhecer sobre a matemática e suas aplicações, eu tive vontade de cursar matemática, pois queria compreender de melhor maneira possível, o meu interesse maior foi o fato de aplicar futuramente a matemática na nossa vida cotidiana, como mencionei anteriormente, criei um gosto grande pelas suas aplicações e tive vontade de aprender mais sobre o assunto, assim como os antigos estudiosos faziam em suas vidas.

(Comentário do aluno bolsista).

Pode-se perceber, também, que o aluno nos dá dicas de que ele acredita que a matemática não está pronta e acabada, é uma evolução ao longo dos tempos (KJELDSEN, 2011). Ao afirmar que gostaria de aprender o modo que os povos antepassados resolviam e faziam matemática ele demonstra ter compreendido a natureza humana da matemática. Ressalta-se o que afirma Jankvist (2009) sobre a História da Matemática colaborar para que o aluno perceba que a Matemática é uma construção humana.

Além desse aprendizado podemos destacar também habilidades e competências adquiridas em relação a apresentações orais e usos de softwares como o Power Point (KJELDSEN, 2011). Podemos observar nas falas a seguir um receio para apresentação oral de um trabalho e, em seguida, como ele evoluiu em relação a isso. A primeira fala foi antes de uma apresentação em um Seminário interno.

Apesar de eu ter achado não ter ficado muito bom [os slides de apresentação no Power Point] como eu disse não consigo nem apresentar para pessoas que eu conheço ainda mais pra quem eu não conheço.

(Comentário do aluno bolsista).

Observa-se o receio do bolsista para apresentar, no entanto, após a apresentação ele se sente mais confiante e com habilidades e competência para esse tipo de comunicação, preferindo em relação ao pôster.

Bom, eu prefiro que seja como na semana de ciência e tecnologia, gostei da experiência apesar de estar um pouco nervoso, mas acho melhor.

(Comentário do aluno bolsista).

Mostra-se, portanto ansioso, mas em seu discurso podemos notar que alguns dos objetivos foram alcançados. Destacamos as habilidades voltadas para a competência 


\section{Davidson Paulo Azevedo Oliveira e Maria Maroni Lopes}

História da matemática em um programa de iniciação científica júnior

leitora, em virtude das pesquisas bibliográficas, e as habilidades voltadas para a resolução de equações do segundo grau. Como: as habilidades geométricas desenvolvidas no método de Al-Khowarizmi; habilidades ligadas à álgebra no método de Viète; habilidades inerentes ao desenvolvimento das equações por meio de construções geométricas, como por exemplo, as realizadas por meio do método de Descartes. O que pode ser reafirmado pela pesquisa de Kjeldsen (2011) na qual ressaltou um potencial importante da História da Matemática.

\section{Considerações finais}

Durante o projeto obteve-se grande conhecimento com relação a metodologia de ensino que possibilitou conhecer mais sobre a matemática e de onde surgiram às fórmulas e equações das quais vemos hoje no nosso dia a dia, como por exemplo, método de Viète na turma de $1^{\underline{0}}$ ano de Edificações, assim como o método de Descartes na turma da Licenciatura. Houve resultados significativos com relação à dinâmica entre o professor com muita busca de informação em livros e também em sites de busca online para que se possam obter mais informações e maior compreensão sobre o assunto estudado.

Após esse estudo reforçamos o papel da História da Matemática pode ser utilizada pelo professor da Educação Básica em sala de aula e que esse uso não se restringe ao desenvolvimento de competências e habilidades matemáticas. Precisa-se, no entanto, aprofundar as pesquisas empíricas em relação a essa tendência na Educação Matemática para analisar as contribuições trazidas para um grupo maior de alunos. Enfim, estender esse tipo de projetos de iniciação científicas júnior para outros alunos a fím de formarmos estudantes com conhecimentos iniciais para a pesquisa científica.

\section{Referências}

BEZERRA, O. M. (2008). Investigação Histórica nas aulas de Matemática: Avaliação de duas experiências. Dissertação (Mestrado em Ensino de Ciências e Matemática). Universidade Federal do Rio Grande do Norte. Natal.

BOYER, C. B. (1996). História da Matemática. (trad. Elza Gomide). São Paulo: Edgard Blucher.

BROLEZZI, A. C. (1991). A arte de contar: uma introdução ao estudo do valor didático da história da matemática. Dissertação (Mestrado em Educação). Universidade de São Paulo. São Paulo. 
CARVALHO, F.; MIORIM, M. A.; BARONE, J.; MUNSIGATTI, J. M.; BEGINATO, R. G.. (2001). Por que Bhaskara? In História \& Educação Matemática. Rio Claro, N. 1. v. 2

FOSSA, J. A. (2006). Recursos pedagógicos para o ensino da matemática a partir das obras de dois matemáticos da Antiguidade. In: MENDES, I. A.; FOSSA, J. A..; VALDÉS, J. E. N. A História como um agente de cognição na Educação Matemática. Porto Alegre: Sulin. 137-182.

JANKVIST, U. T. (2009). A categorization of the 'whys' and 'hows' of using history in mathematics education. Educational Studies in Mathematics, N. 3.v.71, 235-261.

KJELDSEN, T. (2011). Reflections on and benefits of uses of history in mathematics education exemplified by two types of student work in upper secondary school. CERME 7.

MIGUEL, A. (1997). As potencialidades pedagógicas da História da Matemática em questão: argumentos reforçadores e questionadores. Zetetiké. Campinas. N.8. v.5. 73115.

MIGUEL, A.; MIORIN, M. A. (2008). História na Educação Matemática: Propostas e desafios. Belo Horizonte: Autêntica.

MENDES, I. A. (2006). A investigação histórica como agente da cognição matemática na sala de aula. In: MENDES, I. A.; FOSSA, J. A.; VALDÉS, J. (Orgs.). A História como um agente de cognição na Educação Matemática. Porto Alegre: Sulina. 79-136.

NETO, H. M. A coleção História da Matemática para professores: um estudo sobre possibilidades de uso por professores das séries finais do ensino fundamental. Dissertação de Mestrado. Unesp - Rio Claro. 2009.

NOBRE, S. (2006). Equações Algébricas: uma Abordagem Histórica sobre o Processo de Resolução da Equação de $2^{\circ}$ grau. In: SILVA, C. C. (Org.). Estudos de História e Filosofia das Ciências. São Paulo: Editora Livraria da Física. 353-380

PEDROSO, H. A. (2010). Uma breve história da equação do $2^{\circ}$ grau. Revista Eletrônica de Matemática. REMAT. N. 2, p.1-13.

RADFORD, L.; GUÉRETTE, G. (2000). Second degree equations in the classroom: A Babylonian approach. In: V. K. (ed) Using history to teach mathematics. An international perspective. Washington: The Mathematical Association of America. 6975 .

REFATTI, L. R.; BISOGNIN, E. (2005). Aspectos Históricos e Geométricos da Equação Quadrática. Disc. Scientia. Série: Ciências Naturais e Tecnológicas. Santa Maria, N.1.v.6.79-95. 
Davidson Paulo Azevedo Oliveira e Maria Maroni Lopes

História da matemática em um programa de iniciação científica júnior

SILVA, C. M. S. (2001). A História da Matemática e os cursos de formação de Professores. In: CURY, H. N. (org.) Formação de Professores de Matemática: Uma visão multifacetada. Porto Alegre: EDIPUCRS, 129-164

SILVA, C. M. S. (2010). Qual o papel da História da Matemática na Educação matemática? In: VIII Seminário Nacional de História da Matemática. Anais do Seminário Nacional de História da Matemática. Belém.

VARHIDY, C. G. J. L. (2010). Desenho Geométrico: uma Ponte entre a Álgebra e a Geometria: Resolução de Equações pelo Processo Euclidiano. Dissertação (Mestrado Profissional em Educação Matemática). Universidade Federal de Ouro Preto. Ouro Preto. 